\title{
Impactos biopsicossociais do diagnóstico positivo de HPV nos portadores
}

\author{
Biopsychosocial impacts of positive HPV diagnosis in patients \\ Impactos biopsicosociales del diagnóstico positivo de VPH en pacientes
}

Letícia Nogueira Carvalho Costa de Araújo ${ }^{1 *}$, Alex dos Reis Sousa ${ }^{1}$, Eduardo Nunes Tenório1, Kaline Aragão Peixoto ${ }^{1}$, Sara Oliveira Reis ${ }^{1}$, Sarah Menezes Gashti ${ }^{1}$, Thaynara Rodrigues de Oliveira $^{1}$, Gabriela Galdino de Faria Barros ${ }^{1}$.

\section{RESUMO}

Objetivo: Revisar a literatura com o objetivo de elucidar os principais tópicos relacionados ao Papilomavírus Humano (HPV) e analisar o impacto desta infecção na qualidade de vida dos pacientes. Revisão bibliográfica: Classifica-se o HPV como uma Infecção Sexualmente Transmissível (IST) de alta prevalência. Dentre os fatores de risco dessa etiopatogenia, pode-se destacar hábitos de vida e comorbidades, as quais diminuem a resistência imunológica e ocasionam o aparecimento de lesões intraepiteliais. Os portadores tendem a apresentar manifestações assintomáticas ou tardias, de forma que transmitem o vírus sem saber. Embora prevalente, o diagnóstico positivo apresenta impacto negativo na qualidade de vida dos portadores, devido ao preconceito social relacionado a este. Considerações finais: Portanto, nota-se que é fundamental a propagação de informação em massa sobre o HPV, com objetivo de induzir uma maior vacinação e, assim, prevenir lesões de alto risco e atenuar a prevalência deste vírus e os impactos do diagnóstico positivo.

Palavras-chave: Infecção por papilomavírus humano, Papillomavirus humano, Impacto psicossocial.

\begin{abstract}
Objective: To review the principal topics related to Human Papillomavirus (HPV) and to analyze the impact of this infection on patients' quality of life. Bibliographic review: HPV is classified as a highly prevalent Sexually Transmitted Infection (STI). Some of the risk factors of this etiopathogenesis, life habits and comorbidities stand out, which decrease immunological resistance and cause the appearance of intraepithelial lesions. The carriers tend to present asymptomatic or late manifestations, in that way they can transmit it without knowing. Although prevalent, positive diagnosis has a negative impact on patients' quality of life, due to the social prejudice related to it. Although prevalent, positive diagnosis has a negative impact on patients' quality of life, due to the social prejudice related to it. Final considerations: Therefore, it is noted that it is essential to spread mass information about HPV, in order to induce greater vaccination and, thus, prevent high-risk injuries and mitigate the prevalence of this virus and the impacts of positive diagnosis.
\end{abstract}

Key words: Papillomavirus infections, Papillomaviridae, Psychosocial impact.

\section{RESUMEN}

Objetivo: Revisar y analizar los principales temas relacionados con el virus del Papiloma Humano (VPH) y el impacto de esta infección en la calidad de vida de los pacientes. Revisión bibliográfica: Clasifica-de el VPH como una Infección de Transmisión Sexual (ITS) de alta prevalencia. Entre los factores de riesgo de esta etiopatogenia destacan los hábitos de vida y las comorbilidades, que disminuyen las resistencias

${ }^{1}$ Universidade do Planalto Central Apparecido dos Santos (UNICEPLAC), Brasília - DF.

*E-mail: leeticianogueirac@gmail.com 
inmunológicas y provocan la aparición de lesiones intraepiteliales. Los portadores tienden a presentar manifestaciones asintomáticas o tardías, por lo que lo transmiten sin saberlo. Aunque prevalente, el diagnóstico positivo tiene un impacto negativo en la calidad de vida de los pacientes, debido al prejuicio social relacionado con él. Consideraciones finales: Por consiguiente, se señala que es fundamental difundir información masiva sobre el VPH, con el objetivo de inducir una mayor vacunación y, así, prevenir lesiones de alto riesgo y mitigar la prevalencia de este virus y los impactos del diagnóstico positivo.

Palabras clave: Infecciones por papillomavirus, Papillomaviridae, Impacto psicosocial.

\section{INTRODUÇÃO}

O Papilomavírus Humano (HPV) é a etiologia mais comum do câncer de colo de útero e é designado como uma infecção sexualmente transmissível (IST). A maioria dos indivíduos conseguem realizar um clareamento viral, de tal forma que o próprio sistema imunológico consegue eliminar o vírus e regredir a infecção de forma espontânea, porém, ainda existe a parcela dos infectados que não elimina o vírus e transmite a outras pessoas. Por isso, cabe salientar que $80 \%$ dos indivíduos vão ter contato e adquirir uma infecção genital por HPV durante a vida (RIBEIRO DV, et al., 2020; BENNETT KF, et al., 2019; BENNETT KF, et al., 2020).

Preliminarmente, deve-se pontuar que sua classificação varia de acordo com seu potencial oncogênico, sendo que há diversos subtipos de HPV. Dessa maneira, os subtipos de alto risco são classificados como oncogênicos, sendo os principais os tipos 16 e 18 e os de baixo risco classificados como não-oncogênicos, tendo como mais relevantes os tipos 6 e 11 (BENNETT KF, et al., 2019; SHANMUGASUNDARAM S e YOU J, 2017).

Para tanto, observa-se que os principais fatores de risco para a infecção pelo HPV incluem: tabagismo, atividade sexual precoce, múltiplos parceiros, ter outras ISTs, uso de contraceptivos orais por tempo prolongado e baixa imunidade. Nesse contexto, o estresse também é caracterizado como um fator de risco na etiopatogenia, visto que pode causar diminuição da resistência imunológica e propiciar o surgimento de lesões intraepiteliais (GUEDES DHS, et al., 2020; BENNETT KF, et al., 2019; CVITANOVIC H, et al., 2020).

Ainda, sabe-se que seu diagnóstico é complexo, pois muitos indivíduos são assintomáticos e transmitem o vírus aos seus parceiros sem que tenham conhecimento. Por isso, é fundamental realizar a colposcopia e a peniscopia para detectar precocemente as anormalidades a partir da citologia. Atualmente, há pesquisas que buscam implementar a forma de diagnóstico introduzindo o teste primário de HPV, o qual tem como principal característica identificar a existência do vírus, porém, fornecendo maior sensibilidade no reconhecimento de doença pré-cancerosa de alto grau do que a colposcopia (MEDRADO KS, et al., 2017; BENNETT KF, et al., 2019).

Mesmo com sua alta prevalência, há um grande estigma em relação ao diagnóstico positivo do HPV, fator esse que proporciona uma série de fatores negativos biopsicossociais aos seus portadores. Assim, podem afetar a qualidade de vida de algumas mulheres e gerar insegurança em relação à origem e transmissão da infecção, além de afetar diretamente as relações pessoais entre os cônjuges. Ainda, vale ressaltar que muitas mulheres sofrem modificações físicas, emocionais, afetivas, sexuais e sociais após a identificação do HPV (BENNETT KF, et al., 2019; PEREIRA-CALDEIRA NMV, et al., 2020).

Além disso, nota-se que pacientes diagnosticados com HPV têm grande receio em exteriorizar o diagnóstico positivo aos seus familiares e parceiros, devido ao preconceito existente acerca das ISTs. Dessarte, reações negativas de terceiros podem gerar um sentimento de preocupação e rejeição em relação aos portadores. Então, é notório que haja uma barreira para a comunicação do resultado do teste positivo de HPV ao companheiro (BENNETT KF, et al., 2020).

Para tanto, tem-se a vacina contra o HPV como o modo mais eficiente de prevenção, visto que $90 \%$ dos casos de HPV podem ser evitados utilizando-a. Portanto, a junção do rastreamento periódico e da vacinação contra o HPV é fundamental para prevenir o câncer cervical. Por isso, a importância da cobertura vacinal e da sua expansão deve ser informada à população para que não tenha domínio de preconceitos e, dessa 
forma, reduza-se a prevalência do vírus na sociedade (RIBEIRO DV, et al., 2020; TEXEIRA JC e ROTELIMARTINS CM, 2019).

Dessa forma, o objetivo deste artigo foi realizar uma revisão da literatura, por meio de artigos científicos, abordar os fatores biológicos, psicológicos e sociais causados nos portadores de HPV e de que forma esses fatores afetam a vida desses indivíduos.

\section{REVISÃO BIBLIOGRÁFICA}

\section{O vírus}

O Papiloma Vírus Humano (HPV) é um vírus da família Papilloma viridae, vulgarmente conhecido como crista de galo -devido à apresentação das lesões nos indivíduos infectados. Esse vírus, por ser altamente infeccioso, pode contaminar todo indivíduo que possua vida sexual ativa, por meio de contato genital-genital, ou até mesmo o contato genital-manual. Isso deve-se ao fato de que o HPV acomete pele e mucosas, estando incluídos a vagina, a vulva, o colo uterino, o pênis, o ânus e, raramente, a mão, assim, com qualquer tipo de contato, seja ele manual, oral ou genital o indivíduo está suscetível à contração do vírus (MEDRADO KS, et al.,2017; PEREIRA-CALDEIRA NMV, et al., 2020).

Atualmente, sabe-se que existem cerca de 100 tipos de HPV; sendo que desses, aproximadamente 36 causam lesões benignas ou malignas nas regiões genitais de homens e mulheres. As lesões benignas são conhecidas como verrugas, as quais originaram o nome "crista de galo"; e dentre as lesões malignas estão o câncer no colo do útero, sendo este o mais comum, o câncer anogenital, o câncer de cabeça e pescoço e o câncer no pênis (MEDRADO KS, et al., 2017; SHANMUGASUNDARAM S e YOU J, 2017).

Nesse contexto, a fim de otimizar o cuidado com os pacientes, o HPV foi dividido em subtipos, sendo que os subtipos $6,11,40,42,43,44,54,61,70,72$ e 81 possuem células atípicas, as quais têm potencial de causar lesões benignas, porém esporadicamente causam algum risco apreensivo e, por isso, são classificados como de baixo risco para o surgimento de cânceres. Já os subtipos $16,18,31,33,35,39,45$, $51,52,58,59,68,73$ e 82 são considerados de alto risco, por serem frequentemente associados às lesões de alto grau e aos cânceres; dentre os de alto risco, direciona-se maior atenção aos tipos 16 e 18, por serem mais encontrados nos cânceres e carcinomas do que os demais vírus, além de serem responsáveis por $70 \%$ dos casos de câncer de colo de útero (MEDRADO KS, et al., 2017; SHANMUGASUNDARAM S e YOU J, 2017).

Também, vale ressaltar que as pessoas infectadas pelo HPV normalmente não apresentam sintomas, de maneira a manter tal infecção de forma latente e eliminar o vírus espontaneamente em cerca de 1 a 2 anos apenas cerca de $5 \%$ dos portadores apresentam alguma forma de manifestação. Sendo assim, a alta taxa de infecção por HPV em todo o mundo deve-se ao fato de muitas pessoas não terem conhecimento da doença por não apresentarem sintomas e realizarem relações sexuais de forma desprotegida, transmitindo, então, 0 vírus aos parceiros sexuais (MEDRADO KS, et al., 2017; SHANMUGASUNDARAM S e YOU J, 2017).

Desse modo, atualmente o HPV é considerado a IST com maior prevalência no mundo, visto que, no Brasil, em torno de 54\% das pessoas entre 16 e 25 anos são infectadas e, no mundo, segundo dados da Organização Mundial de Saúde (OMS), uma em cada dez pessoas está infectada pelo HPV (PEREIRACALDEIRA NMV, et al., 2020).

Cabe destacar também que, ainda que o vírus tenha potencial de acometer ambos os sexos, as mulheres são mais frequentemente acometidas e os prejuízos nelas são soberanos devido à presença de uma mucosa genital mais fina e com maior extensão, além disso, os principais genótipos de HPV que causam verrugas anogenitais (AGWs) são os 6 e 11, que são de baixo risco carcinogênico. Por isso, apesar de a qualidade de vida de ambos os sexos ser afetada, percebe-se que a feminina é mais prejudicada do que a masculina, tanto por aspectos de preconceito da sociedade quanto pela maior prevalência do câncer cervical em relação aos outros tipos de cânceres (PEREIRA-CALDEIRA NMV, et al., 2020; SHANMUGASUNDARAM S e YOU J, 2017). 


\section{Fatores de risco}

Vários fatores podem influenciar e colocar em risco mulheres e homens com relação à infecção pelo HPV. Com isso, estudos de coorte foram realizados em 3 regiões americanas: Baltimore, Seattle e outras cidades menores, demonstrando que mulheres que apresentam número de parceiros elevado -maior ou igual a 5aumentam as chances de infecção ou reinfecção por HPV de maneira circunstancial, visto que, muitas vezes, não se sabe se o parceiro está infectado, aumentando, dessa forma, as chances de infecção ou reinfecção por um novo subtipo do HPV de alto risco (GRAVITT PE e WINER RL, 2017).

Em relação ao uso de anticoncepcionais orais, sabe-se que podem ser um problema, dependendo do tempo de utilização, pois podem contribuir para uma evolução maligna das lesões. Em geral, de acordo com - Conselho Brasileiro de Medicina, se uma pessoa utilizar por 5 anos esse método, tal uso não se tornará um influenciador direto na evolução das lesões para a malignidade. Entretanto, o uso prolongado do método por período superior a 10 anos tornar-se-á um fator de risco para o desenvolvimento de lesões malignas em mulheres que já tiveram contato com o vírus, principalmente os tipos oncogênicos (ANDRADE LMRL, et al., 2017).

Ainda nessa conjuntura, nota-se que a presença de outras infecções sexualmente transmissíveis também significa fator de risco para a prevalência do HPV. A exemplo dos casos de contaminação por Vírus da Imunodeficiência Humana (HIV). Esse vírus age neutralizando o sistema imune do organismo e facilitando a progressão da infecção pelo HPV, devido ao fato de as defesas estarem deficitárias e uma resposta direta não ser possível no combate a essa infecção. Sendo assim, o HIV torna-se um impulsionador da infecção por HPV, pois causa imunodeficiência no organismo hospedeiro (MEDRADO KS, et al., 2017).

Vale ressaltar, também, que o início da atividade sexual de maneira precoce torna-se um problema, pois a orientação sobre os métodos de prevenção da infecção por HPV ainda é escassa. Portanto, torna-se de suma importância que se saiba que as lesões decorrentes da infecção por HPV podem levar de semanas a anos para surgirem, assim, pessoas jovens podem estar infectadas, porém, somente saberão na meia idade, quando as lesões aparecem em virtude do seu tempo de evolução. Contudo, devido a manifestações clínicas tardias, a procura ao médico tende a ocorrer quando as lesões se tornam evidentes e causam alterações no organismo, como sangramentos no momento do ato sexual, lesões em formato de couve-flor -lesões com relevo- de tamanhos variados, sensação de desconforto na área genital e prurido (ANDRADE LMRL, et al., 2017; MEDRADO KS, et al., 2017; PEREIRA-CALDEIRA NMV, et al., 2017).

\section{Diagnóstico}

O exame de papanicolau ou exame citológico é o único método de rastreio do câncer cervical no sistema público de saúde brasileiro desde sua inclusão na década de 1970. Embora o teste de papanicolau seja a ferramenta de padrão de rastreamento, há limitações de sensibilidade e especificidade. Esse certifica se há alterações significativas na ectocérvice das mulheres. Assim, os resultados positivos podem variar entre displasia leve (NIC I), displasia moderada (NIC II), displasia acentuada ou carcinoma "in situ" (NIC III) (TAVARES MCSA, et al., 2020; LEVI JE, et al., 2019).

Por outro lado, os testes de HPV, que identificam DNA viral ou mRNA, são usados para uma melhor triagem de mulheres que possuem resultados do exame de papanicolau apresentando anormalidades. Isso é possível devido à alta taxa de detecção dos testes de HPV em verificar neoplasia intraepitelial cervical de grau 3 (NIC III) e lesões de câncer cervical, que varia superiormente entre $60 \%-70 \%$ quando comparados com a citologia (LEVI JE, et al., 2019).

\section{Rastreamento}

No Brasil, o rastreamento do câncer do colo do útero é feito pelo exame citológico. Sendo assim, o Instituto Brasileiro do Câncer recomenda o rastreamento em mulheres dos 25 aos 64 anos, o papanicolau é realizado durante 2 anos consecutivos, com esses resultados negativos, os próximos devem ser feitos a cada 3 anos. $O$ rastreio é interrompido aos 64 anos em mulheres que tenham 2 exames consecutivos com resultado negativo nos últimos 5 anos (BARBOSA IR, 2017). 
Cabe destacar que anteriormente a maioria dos programas de rastreamento costumavam usar a citologia como método de detecção precoce das anomalias cervicais causadas pelo HPV. No entanto, utilizar o teste de HPV como método de rastreio traz maior segurança por ter maior sensibilidade para detectar anormalidades cervicais de alto grau. Dessa forma, países mais desenvolvidos, implementaram ou implementarão o teste primário de HPV nos seus programas de triagem (BENNETT KF, et al., 2019).

Assim, pelo fato de o teste de HPV ser mais sensível e ter um alto valor preditivo negativo, há possibilidade de aumentar os intervalos entre as coletas, pois o risco de desenvolver alguma lesão ou câncer de 5 a 10 anos é baixo. Ainda, sabe-se que a realização da triagem numerosa por meio de testes moleculares é viável em solo brasileiro e isso aperfeiçoaria o rastreamento, bem como diagnósticos precisos de lesões precursoras e cânceres cervicais. A recomendação internacional e nacional é que o teste de HPV seja feito em mulheres com 30 anos ou mais (LEVI JE, et al., 2019; CALEIA Al, et al., 2020).

\section{Vacina e Prevenção}

A vacinação contra o HPV surgiu como uma grande aliada no combate às lesões verrucosas, cervicais e malignas que acometem mulheres e homens, as quais são responsáveis por praticamente todos os diagnósticos de câncer cervical e lesões intraepiteliais de alto grau em todo o mundo. A criação dessa ferramenta contra o papilomavírus humano fez-se necessária à medida que o HPV se tornou a infecção sexualmente transmissível mais comum no mundo (MEDRADO KS, et al., 2017; RIBEIRO DV, et al., 2020).

Para tanto, a vacina buscou de maneira inteligente diminuir a prevalência dos subtipos do vírus HPV que mais causam transtornos e riscos à sociedade no desenvolvimento de neoplasias cervicais. Dessa forma, a vacina quadrivalente, utilizada pelo Sistema Único de Saúde (SUS), possui como finalidade induzir as defesas do corpo contra os tipos 6 e 11, responsáveis por mais de 90\% dos casos de verrugas anogenitais e os tipos 16 e 18, os quais são os tipos mais relacionados ao desenvolvimento de neoplasias e câncer de colo de útero (TEIXEIRA JC e ROTELI-MARTINS CM, 2019).

Antes da vacinação, a única ferramenta que era utilizada para detecção e prevenção de alterações provenientes do vírus era o exame citopatológico, conhecido como Papanicolau, mas apenas esse exame não era suficiente, haja vista que não é aplicável em homens, os quais também são vetores do vírus. Assim, com o auxílio da vacina essa detecção/prevenção tornou-se mais eficaz (RIBEIRO DV, et al., 2020; MEDRADO KS, et al., 2017).

Ademais, sabe-se que, apesar de a vacina não induzir proteção contra os outros tipos oncogênicos, como os tipos 31, 32, 35 e 45, no Brasil, o uso da vacina quadrivalente foi muito importante na prevenção das lesões de alto risco, diminuindo os diagnósticos de forma bastante expressiva. Com isso, é possível perceber que a imunização trouxe somente resultados positivos, em todos os lugares em que foi e está sendo utilizada, demonstrando ser uma medida válida e de alto valor na prevenção de verrugas e lesões potencialmente malignas (TEIXEIRA, JC e ROTELI-MARTINS, CM, 2019; RIBEIRO DV, et al., 2020; SHANMUGASUNDARAM S e YOU J, 2017).

\section{Qualidade de vida dos portadores}

A análise dos impactos causados nos portadores de HPV é de fundamental importância, tendo em vista que devem ser instituídas ações que diminuam os danos físicos, psicológicos, sociais e econômicos na vida dessas pessoas. Diante do exposto, nota-se que ao receber o diagnóstico positivo, tais pessoas sofrem uma série de mudanças, desde físicas, emocionais, sociais até sexuais e afetivas (PEREIRA-CALDEIRA NMV, et al., 2020; ARROSSIA S, et al., 2020).

Devido a inúmeros aspectos, as mulheres são potencialmente mais afetadas do que os homens ao se tratar da qualidade de vida, por isso, primeiramente e principalmente serão avaliados os danos causados a elas. Então, considerando os aspectos físicos, nota-se que tais pacientes possuem prurido na vulva e dor no abdômen e na genitália -a qual manifesta-se ao executar afazeres do dia a dia-, além de sangramento e desconforto durante as relações sexuais (PEREIRA-CALDEIRA NMV, et al., 2020). 
No que se refere às alterações sexuais, percebe-se que, em decorrência das alterações físicas, como prurido, dor e sangramento, as mulheres tornam-se instáveis e perdem a libido, chegando, em alguns casos, à interrupção da atividade sexual do casal. Dessa forma, os aspectos afetivos estão diretamente ligados aos aspectos sexuais, uma vez que em decorrência das mudanças citadas, surgem contratempos matrimoniais. Além disso, vem à tona a desconfiança com seus parceiros frente ao diagnóstico positivo para HPV, pois as mulheres relacionam-no a relacionamentos extraconjugais (PEREIRA-CALDEIRA NMV, et al., 2020; ARROSSIA S, et al., 2020).

Ao tratar-se das mudanças emocionais, observa-se o medo do diagnóstico e das consequências da infecção, tristeza e preocupação; nesse sentido, relata-se, ainda, a vergonha da exposição do diagnóstico às pessoas próximas, pois as ISTs são diretamente relacionadas à imoralidade e à promiscuidade (ARROSSIA S, et al., 2020).

No que ainda concerne às alterações sociais, observa-se uma maior desânimo em gozar de atividades coletivas, as quais antes eram realizadas com facilidade e como forma de aumentar o convívio social; além disso, percebe-se que muitas dessas mulheres têm sua vida profissional afetada, devido ao absentismo laboral, em decorrência de consultas ou do tratamento da doença em si, os quais muitas vezes precisam ser realizados durante o horário de trabalho e podem causar a demissão delas (PEREIRA-CALDEIRA NMV, et al., 2020).

Ao observar os impactos causados na vida dos portadores de HPV homens, nota-se que as verrugas anogenitais são bastante frequentes, estando presentes em 30 a $40 \%$ dos casos. Porém, percebe-se que os homossexuais tiveram a sua qualidade de vida potencialmente mais afetada, tendo tido consequências principalmente relacionadas às alterações físicas, ao constrangimento e à vida sexual (CAVASSAN CC, et al., 2017)

Nesse âmbito, verifica-se que tais impactos negativos podem ser evitados ou mitigados com uma melhor informação da população quanto aos tipos e perigos de cada tipo de HPV, tendo em vista que nem todos os subtipos do vírus têm potencial de evoluir para cânceres. Assim, como preconizado pela OMS, o profissional de saúde, ao informar o diagnóstico ao paciente, deve realizar uma explicação do que é o HPV, de como ocorre a sua transmissão e qual a sua relação com o câncer cervical, diferenciá-lo do Vírus da Imunodeficiência Humana (HIV), além de diferenciar a diferença de positividade viral e presença de cânceres; a fim de minimizar perdas na qualidade de vida dos pacientes (MEDRADO KS, et al., 2017; VICTORIA SA, et al., 2020; ARROSSIA S, et al., 2020).

Perante o exposto, entende-se como fulcral as redes de apoio aos portadores de HPV -as quais poderão ser relacionadas à família, aos profissionais de saúde, aos membros de igrejas, aos amigos e às outras pessoas do convívio social dos portadores-, tendo em vista que serão essenciais para familiaridade dos pacientes com o diagnóstico, para o menor julgamento da sociedade e para uma diminuição dos impactos na sua qualidade de vida. Assim, o estigma em torno desse tema ficará cada vez menor, colaborando para uma melhor adesão aos tratamentos e à vacinação, fato esse que levará, gradativamente, a uma menor prevalência do vírus no Brasil e no mundo (PEREIRA-CALDEIRA NMV, et al., 2020; VICTORIA SA, et al., 2020; POT M, et al., 2017).

\section{CONSIDERAÇÕES FINAIS}

Verificou-se neste trabalho a relevância do HPV, considerado uma IST de alta prevalência, podendo influenciar o bem-estar de homens e mulheres. Destarte, constatou-se que apesar de acometer ambos os sexos, as mulheres são mais prejudicadas, uma vez que estão mais sujeitas a prejulgamentos sociais, além de possuírem fatores anatômicos os quais propiciam a infecção, como a presença de mucosa genital mais fina e com maior extensão. Desse modo, foi visto durante o estudo que a infecção por esse vírus acarreta no desequilíbrio biopsicossocial dos pacientes, principalmente com prejuízos sociais e sexuais. Em função disso, nota-se a importância da vacinação como método eficiente de prevenção de lesões de alto risco e, também, como forma de mitigação de preconceitos. 


\section{REFERÊNCIAS}

1. ANDRADE LMRL, et al. Infecção pelo papilomavirus humano em mulheres com resultados de exames citopatológicos normais: uma revisão sistemática. Brazilian Journal of Surgery and Clinical Research (BJSCR), 2017; 19(2): $162-169$.

2. ARROSSI S, et al. Psycho-social impact of positive human papillomavirus testing in Jujuy, Argentina results from the Psycho-Estampa study. Preventive medicine reports, 2020; 18: 101070.

3. BARBOSA IR. Regional and socioeconomic differences in the coverage of the Papanicolau test in Brazil: data from the Brazilian health survey 2013. Revista Brasileira de Ginecologia e Obstetrícia, 2017; 39(9): 480-487.

4. BENNETT KF, et al. Concerns about disclosing a high-risk cervical human papillomavirus (HPV) infection to a sexual partner: a systematic review and thematic synthesis. BMJ sexual \& reproductive health, 2020; 47(1): 17-26.

5. BENNETT KF, et al. The psychosexual impact of testing positive for high-risk cervical human papillomavirus (HPV): a systematic review. Psycho-oncology, 2019; 28(10): 1959-1970.

6. CALEIA Al, et al. Self-sampling as a plausible alternative to screen cervical cancer precursor lesions in a population with low adherence to screening: a systematic review. Acta cytologica, 2020; 64(4): 332-343.

7. CAMARGO CC, et al. Quality of life in men diagnosed with anogenital warts. Anais brasileiros de dermatologia, 2017; 92(3): 427-429.

8. CVITANOVIĆ H, et al. Determination of Psychological Stress, Serum Immune Parameters, and Cortisol Levels in Patients with Human Papilloma Virus. Clinical therapeutics, 2020; 42(5): 783-79.

9. DOMINIAK-FELDEN G, et al. Impact of human papillomavirus-related genital diseases on quality of life and psychosocial wellbeing: results of an observational, health-related quality of life study in the UK. BMC public health, 2013; 13(1): 1-11.

10. GRAVITT PE, WINER RL. Natural history of HPV infection across the lifespan: role of viral latency. Viruses, 2017; 9(10): 267.

11. GUEDES DHS, et al. Fatores associados ao papilomavírus humano entre mulheres com câncer de colo uterino. Rev Rene, 2020; 21: e43681.

12. LEVI JE, et al. High-risk HPV testing in primary screening for cervical cancer in the public health system, São Paulo, Brazil. Cancer Prevention Research, 2019; 12(8): 539-546.

13. MEDRADO KS, et al. Papiloma vírus humano (hpv): revisão bibliográfica. Saúde \& ciência em ação, 2017; 3(2): 5263.

14. MENON S, et al. Human papilloma virus infection in HIV-infected women in Belgium: implications for prophylactic vaccines within this subpopulation. European Journal of Cancer Prevention, 2018; 27(1): 46-53.

15. PEREIRA-CALDEIRA NMV, et al. Instrumentos para avaliação da qualidade de vida em indivíduos com papilomavírus humano. Revista Brasileira de Enfermagem, 2019; 72(5): 1363-1369.

16. PEREIRA-CALDEIRA NMV, et al. Quality of Life for Women with Human Papillomavirus-induced Lesions. Revista Brasileira de Ginecologia e Obstetrícia, 2020; 42(4): 211-217.

17. POT $\mathrm{M}$, et al. Motivational and contextual determinants of HPV-vaccination uptake: a longitudinal study among mothers of girls invited for the HPV-vaccination. Preventive medicine, 2017; 100: 41-49.

18. RIBEIRO DV, et al. The impact of the HPV vaccine on the world: initial outcomes and challenges. DST j. bras. doenças sex. transm, 2020: 1-7.

19. SHANMUGASUNDARAM S, YOU J. Targeting persistent human papillomavirus infection. Viruses, $2017 ; 9(8): 229$.

20. TAVARES MCSA, et al. Avaliação dos resultados do rastreamento citopatológico e dos fatores de risco de mulheres submetidas ao exame de Papanicolaou em uma maternidade-escola de Fortaleza, Ceará, Brasil. Citopatologia: Jornal Oficial da Sociedade Britânica de Citologia Clínica, 2020. Disponível em: https://onlinelibrary.wiley.com/doi/10.1111/cyt.12883 Acesso em: 10 de abril sw 2021.

21. TEIXEIRA JC, ROTELI-MARTINS CM. HPV vaccines: separating myths from reality. Revista Brasileira de Ginecologia e Obstetrícia, 2019; 41(7): 417-418.

22. VICTORIA SA, et al. Knowledge and perceptions regarding triage among human papillomavirus-tested women: $A$ qualitative study of perspectives of low-income women in Argentina. Women's Health, 2020; 16: 1745506520976011. 